auditing senior clinicians exhibited multiple discrepancies. This raises doubts as to the robustness of mortality data. We have identified a need to review the practice including the accurate completion of death certificates.

\section{P219 TEN YEAR MORTALITY IN A PRIMARY CARE COPD COHORT: MULTIDIMENSIONAL INDEX BOD MORE DISCRIMINANT THAN GOLD STAGING}

doi:10.1136/thoraxjnl-2011-201054c.219

${ }^{1} \mathrm{~N}$ P Keaney, ${ }^{2} \mathrm{~K}$ Ansari, ${ }^{2} \mathrm{~J}$ Munby, ${ }^{2} \mathrm{M}$ Price, ${ }^{1} \mathrm{~A}$ Kay, ${ }^{1} \mathrm{I} \mathrm{K}$ Taylor. ${ }^{1}$ City Hospitals Sunderland, Sunderland, UK; ${ }^{2}$ University of Sunderland, Sunderland, UK

Of potential prognostic variables for COPD to use in a multidimensional staging tool, BMI, severity of airflow obstruction $\left(\mathrm{FEV}_{1} \%\right.$ predicted) and the MRC Dyspnoea Score (BOD) have been shown to be useful for a more complete assessment of the impact of the disease. ${ }^{1}$ In 1999-2002 we identified 431 patients (208 women) with COPD in primary care surgeries and recorded their BOD scores (maximum 7). For men and women (mean \pm SD): age was $66 \pm 10$ and $64 \pm 10$; pack/years $34 \pm 19$ and $34 \pm 18$; BMI $27 \pm 5$ and $25 \pm 6$; $\mathrm{FEV}_{1} \%$ predicted $55 \pm 15$ and $57 \pm 16$; and MRC Dyspnoea Score $2.6 \pm 1.0$ and $2.6 \pm 1.0$; with BOD scores $1.9 \pm 1.5$ and $2.0 \pm 1.6$ respectively. The low mean $\mathrm{BOD}$ scores indicate the mainly moderate severity for this primary care cohort (only one subject had an MRC score of 5). Because of the similarities in these variables for men and women further analysis is of the whole cohort. Mortality was assessed in October 2010 and a Kaplan-Meier analysis for those with BOD scores 0 and 1 shows $80 \%$ and $75 \%$ probability of survival, whereas for a BOD score of $>4$ the 10 -year survival was $<20 \%$. By way of contrast GOLD stages 1 and 2 had a $75 \%$ and $60 \%$ survival with Stage 4 showing a $60 \%$ survival. The Cox regression model (Abstract P219 table 1) demonstrated that BOD was a better predictor of survival than age and that smoking history was a significant covariate. Ten year survival was $<10 \%$ when smoking history (with age and co-morbidity score) was added to a BOD score of $>4$ in a Kaplan-Meier plot.

Abstract P219 Table 1 Cox regression model with covariates influencing COPD mortality. (BOD quartiles: $0,1,2-4$ and $>4$ )

\begin{tabular}{llllll}
\hline & B & SE & Wald (df=1) & p Value & Exp (B) (95\% CI) \\
\hline BOD quartiles & 0.627 & 0.126 & 24.889 & $<0.001$ & $1.873(1.464$ to 2.396$)$ \\
Age & 0.055 & 0.012 & 21.818 & $<0.001$ & $1.057(1.033$ to 1.082$)$ \\
Pack/years & 0.024 & 0.006 & 15.695 & $<0.001$ & $1.024(1.012$ to 1.037$)$
\end{tabular}

Conclusion $\mathrm{BOD}$, a multidimensional index of the clinical impact of COPD is valid for a 10 -year prognosis and outperforms GOLD staging over that period.

\section{REFERENCE}

1. Celli BR, Calverley PM, Rennard SI, et al. Proposal for a multidimensional staging system for chronic obstructive pulmonary disease. Respir Med 2005;99:1546-54.

\section{P220 TRANSFER FACTOR AND ARTERIAL OXYGEN PARTIAL PRESSURE ARE PREDICTORS OF SURVIVAL IN HOSPITAL OUTPATIENTS WITH COPD}

doi:10.1136/thoraxjnl-2011-201054c.220

A K Boutou, D Shrikrishna, R J Tanner, C Smith, J L Kelly, G Coissi, M I Polkey, N S Hopkinson. NIHR Respiratory Biomedical Research Unit at Royal Brompton and Harefield NHS Foundation Trust and Imperial College, London, UK

Introduction COPD is a disorder characterised by high morbidity and mortality. Although several parameters have been used to predict survival among COPD patients, most of the information on the prognostic value of pulmonary function comes from studies, either conducted in selected COPD populations or where only simple spirometry was measured. Few studies have comprehensively assessed lung function parameters and investigated their impact on survival; a prior smaller study from our group suggested carbon monoxide gas transfer may have prognostic value. ${ }^{1}$

Objective The study aimed to identify potential predictors of survival in a cohort of stable COPD outpatients.

Methods Data from patients, who had their first full lung function tests including blood gas analysis between February 1996 and May 2010 were extracted from the hospital's clinical COPD database. Patients with major co morbidities, such as malignancy, chronic renal failure and chronic heart failure were excluded. Survival data were available for all patients, until May 2011. Demographic data, $\mathrm{PaO}_{2}$ and $\mathrm{PaCO}_{2}$, transfer factor, and plethysmographic lung volumes were initially entered in a univariate regression model. Age, Body Mass Index (BMI), $\mathrm{FEV}_{1} \%$ predicted, $\mathrm{FEV}_{1} / \mathrm{FVC}, \mathrm{TLC} \%$ predicted, TLCOc\% predicted, KCOc\% predicted, $\mathrm{RV} \%$ predicted, IC/TLC, $\mathrm{PaCO}_{2}$ and $\mathrm{PaO}_{2}$, were found to be univariately associated with survival and then entered in a stepwise Cox regression analysis model. Corresponding HRs and 95\% CI were calculated for each independent predictor.

Results Data were available for 641 patients ( $62.2 \%$ male); mean age $61.9 \pm 10.2$ years, $\mathrm{FEV}_{1} \quad 38.4 \pm 19.7 \%$ and $\mathrm{BMI} 24.3 \pm 5.3 \mathrm{~kg} / \mathrm{m}^{2}$ Median survival was 92.9 months. Survival rates at 3 and 5 years (all cause mortality) were 0.88 and 0.62 . In the total population, age (HR 1.05, 95\% CI 1.03 to 1.07$), \mathrm{PaO}_{2}$ (HR 0.843, 95\% CI 0.76 to 0.934 ) and TLCOc\% (HR 0.975 , 95\%CI to 0.965 to 0.986 ) independently predicted survival. Abstract P220 Figure 1 presents the Kaplan-Meier survival curves, adjusted for age and $\mathrm{PO}_{2}$, for the two population groups, separated using the TLCOc\% median value as a cut-off point ( $>38.0$ and $=38.0 \%$ predicted).

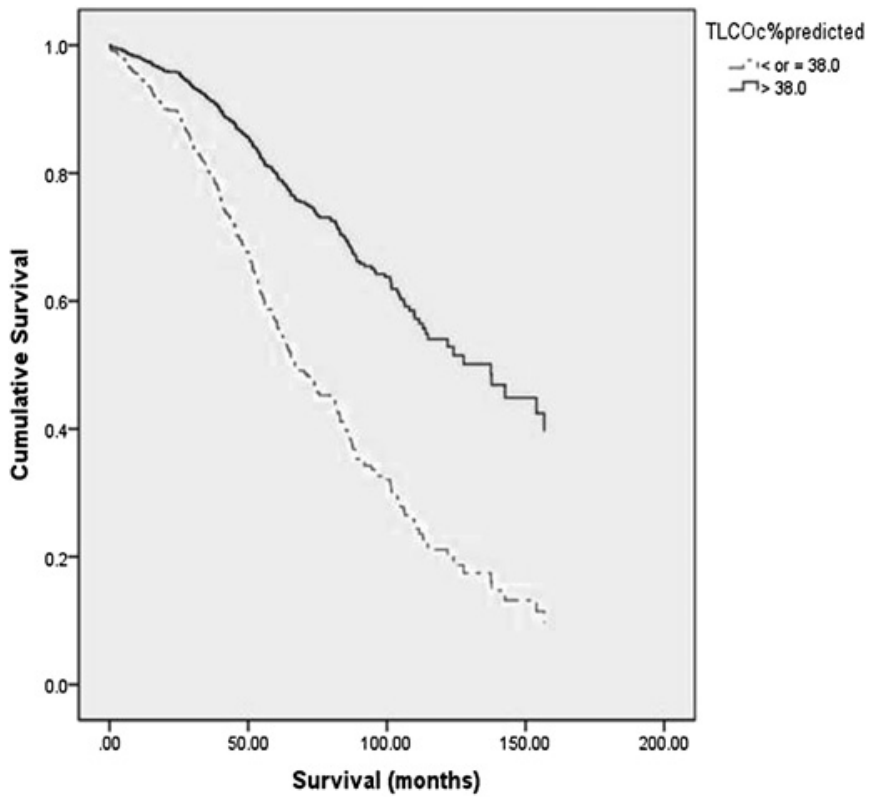

Abstract P220 Figure 1 Survival curves adjusted for $\mathrm{PO}_{2}$ and age for the two patient groups, separated according to $\mathrm{TLCO} \%$ predicted value.

Conclusions Gas transfer measurement provides additional prognostic information compared to spirometry.

\section{REFERENCE}

1. Moore AJ, Soler RS, Cetti EJ, et al. Sniff nasal inspiratory pressure versus IC/TLC ratio as predictors of mortality in COPD. Respir Med 2010;104:1319-25. 